\title{
Degradation Behavior of Silk Nanoparticles-Enzyme Responsiveness
}

\author{
Thidarat Wongpinyochit, ${ }^{\dagger}$ Blair F. Johnston, ${ }^{\dagger}$ and F. Philipp Seib ${ }^{*},+\ddagger$ \\ ${ }^{\dagger}$ Strathclyde Institute of Pharmacy and Biomedical Sciences, University of Strathclyde, 161 Cathedral Street, Glasgow G4 0RE, U.K. \\ ${ }^{\ddagger}$ Leibniz Institute of Polymer Research Dresden, Max Bergmann Center of Biomaterials Dresden, Hohe Strasse 6, 01069 Dresden, \\ Germany
}

Supporting Information

ABSTRACT: Silk nanoparticles are viewed as promising vectors for intracellular drug delivery as they can be taken up into cells by endocytosis and trafficked to lysosomes, where lysosomal enzymes and the low $\mathrm{pH}$ trigger payload release. However, the subsequent degradation of the silk nanoparticles themselves still requires study. Here, we report the responsiveness of native and PEGylated silk nanoparticles to degradation following exposure to proteolytic enzymes (protease XIV and $\alpha$-chymotrypsin) and papain, a cysteine protease. Both native and PEGylated silk nanoparticles showed similar degradation behavior over a 20 day exposure period (degradation rate: protease XIV > papain $\gg \alpha$-chymotrypsin). Within 1 day, the silk nanoparticles were rapidly degraded by protease XIV, resulting in a $\sim 50 \%$ mass loss, an increase in particle size, and a reduction in the amorphous content of the silk secondary structure. By contrast, 10 days of papain treatment was necessary to observe any significant change in nanoparticle properties, and $\alpha$-chymotrypsin treatment had no effect on silk nanoparticle characteristics over the 20-day study period. Silk nanoparticles were also exposed ex vivo to mammalian lysosomal enzyme preparations to mimic the complex lysosomal microenvironment. Preliminary results indicated a $45 \%$ reduction in the silk nanoparticle size over a 5-day exposure. Overall, the results demonstrate that silk nanoparticles undergo enzymatic degradation, but the extent and kinetics are enzyme-specific.

KEYWORDS: silk nanoparticles, biodegradation, proteolytic enzymes, ex vivo lysosomal enzymes

\section{INTRODUCTION}

The biopolymer silk has a long clinical track record, as silk from domesticated silkworms (Bombyx mori) has been used in medical applications for many centuries. ${ }^{1}$ Even today, silk remains the preferred material for specialized suture applications (e.g., eye surgery) ${ }^{1}$ due to its exquisite handling and toughness. ${ }^{2,3}$ Recently, silk has been approved for human use in surgical meshes (Allergan Inc., U.S.A.) designed for soft tissue repair and reconstruction. ${ }^{4}$ However, silk is also a promising biopolymer for emerging biomedical applications, because of (i) the extensive clinical experience with silk, (ii) the all-aqueous silk processing technology, (iii) the ability of silk to stabilize and protect therapeutic payloads, and (iv) the capacity to reverse engineer silk into films, scaffolds, hydrogels, and micro- and nanoparticles (reviewed in refs 5-7). Silk nanoparticles can be surface decorated with polyethylene glycol (PEG) to improve colloidal stability in physiological fluids and to allow evasion of immune recognition.,

Native and PEGylated silk nanoparticles (size approximately $100 \mathrm{~nm}$ ) are often proposed for solid tumor drug targeting (reviewed in ref 5). Following intravenous dosing, these nanoparticles circulate in the blood, extravasate at the tumor site due to leaky blood vessels, and accumulate due to impaired lymphatic drainage. This phenomenon is commonly referred to as the "enhanced permeation and retention" (EPR) effect, ${ }^{10,11}$ but full clinical exploitation of the EPR effect remains to be realized. ${ }^{12,13}$ The payloads of nanoparticles can differ widely, but the nanoparticles must reach the tumor microenvironment and must often deliver the payload to a specific intracellular destination to elicit the desired pharmacological effect. For example, native and PEGylated silk nanoparticles are typically designed for lysosomotropic drug delivery; ${ }^{8,14}$ therefore, they need to traffic into lysosomes, where the low $\mathrm{pH}$ and lysosomal enzymes trigger payload release. ${ }^{15}$ However, the subsequent fate and the material properties of the native and PEGylated silk nanoparticles that accumulate within lysosomes is unknown.

The silk protein is considered biodegradable because it is sensitive to proteolytic enzymes (e.g., protease $\mathrm{K}$, protease XIV, collagenase, and $\alpha$-chymotrypsin) and enzyme-catalyzed hydrolysis reactions. ${ }^{16}$ The hydrophilic amorphous segments within the silk heavy chain, as well as the $\mathrm{C}$ - and $\mathrm{N}$-terminal

Received: January 8, 2018

Accepted: February 7, 2018

Published: February 7, 2018 
sequences (which consist of completely nonrepeating amino acid residues), are particularly susceptible to proteolytic degradation. The degradation of monolithic silk films ${ }^{17}$ and porous silk scaffolds ${ }^{18}$ has been studied extensively both in vitro and in vivo. However, the degradation behavior is influenced by a number of factors, including (i) silk secondary structures (e.g., beta-sheet content), (ii) silk format (e.g., monolithic film versus porous scaffold), (iii) exposure time, and (iv) enzyme types (these vary among cells as well as subcellular locations). ${ }^{17-20}$

The degradation products of silk-based biomaterials are expected to be noncytotoxic. ${ }^{21}$ However, the enzymatic degradation behavior of silk nanoparticles is poorly defined, especially for silk nanoparticles intended for lysosomotropic drug delivery. Our goal was therefore to investigate the degradation of native and PEGylated silk nanoparticles by monitoring the secondary structure, zeta potential, particle size, mass loss, and morphology following exposure to protease enzymes (protease XIV and $\alpha$-chymotrypsin) and a cysteine protease, papain, which resembles the mammalian lysosomal enzymes, cathepsins $\mathrm{B}, \mathrm{H}, \mathrm{L}$, and $\mathrm{S}^{22}$ The morphology and particle size distribution of native and PEGylated silk nanoparticles were also examined following ex vivo exposure to enzymes from lysosomes isolated by subcellular fractionation of rat liver.

\section{EXPERIMENTAL METHODS}

Preparation of Reverse Engineered Silk Solution. Silk was extracted from Bombyx mori silk cocoons using a 60 min degumming time and was fully reverse engineered to yield an aqueous silk solution, as described previously. ${ }^{8}$

Preparation of Native and PEGylated Silk Nanoparticles. Silk nanoparticles were generated using nanoprecipitation; a video format for the preparation of native silk nanoparticles has been reported previously. ${ }^{23}$ When indicated, the silk nanoparticles were surface modified with TST-activated mPEG 5000, as reported. ${ }^{8}$ The native and PEGylated silk nanoparticles were stored at $4{ }^{\circ} \mathrm{C}$ until use.

Isolation of Lysosomes from Rat Liver. Differential and gradient centrifugation was used to isolate rat liver lysosomes. The lysosomal preparation was characterized and subjected to quality control measures (detailed in the Supplementary Methods).

Degradation of Native and PEGylated Silk Nanoparticles by Protease Enzymes and a Lysosomal-Like Enzyme. Protease XIV from Streptomyces griseus (3.5 units per mg enzyme), $\alpha$-chymotrypsin from bovine pancreas (40 units per mg enzyme), and papain (lysosomal-like enzyme) from Carica papaya latex (10 units per $\mathrm{mg}$ enzyme) were purchased from Sigma-Aldrich (St. Louis, MO, U.S.A.). The enzymatic activities were fixed at 3.5 enzyme units (U) for all subsequent degradation studies. Therefore, $1 \mathrm{mg} / \mathrm{mL}$ protease XIV, $0.0875 \mathrm{mg} / \mathrm{mL} \alpha$-chymotrypsin, and $0.35 \mathrm{mg} / \mathrm{mL}$ papain were freshly prepared by dissolving the respective enzyme powder in ultrapure water. The $10 \mathrm{mg} / \mathrm{mL}$ native and PEGylated silk nanoparticles were exposed to these enzymes, and the enzymes were recharged (i.e., keeping enzyme activity at $3.5 \mathrm{U}$ ) every 5 days for up to 20 days. All samples were incubated at $37{ }^{\circ} \mathrm{C}$ and analyzed at $1,3,5,10$, and 20 days.

Ex Vivo Degradation of Native and PEGylated Silk Nanoparticles Exposed to Lysosomal Enzymes. A $0.5 \mathrm{~mL}$ lysosomerich fraction was added to a $0.1 \mathrm{~mL}$ Slide-A-Lyzer Mini Dialysis Device (MWCO $3500 \mathrm{~g} \mathrm{mol-1;}$ Thermo Scientific, Waltham, MA, U.S.A.) and was dialyzed against $1 \mathrm{~L}$ ultrapure water at $4{ }^{\circ} \mathrm{C}$ for $24 \mathrm{~h}$ to remove the buffer. The functional capacity of this buffer-free lysosomal-rich fraction was verified with the $N$-acetylglucosaminidase (NAG) assay. Native and PEGylated silk nanoparticles were treated with $3.5 \mathrm{U} / \mathrm{mL}$ lysosomal enzymes (enzyme activity $0.105 \mathrm{U} / \mathrm{mL}$ ): 30 $\mu \mathrm{L}$ of $3.33 \mathrm{mg} / \mathrm{mL}$ native and PEGylated silk nanoparticles containing $0.1 \mathrm{mg}$ nanoparticles were treated with $333 \mu \mathrm{L}$ of lysosomal enzymes in $400 \mu \mathrm{L}$ of acidified water, $\mathrm{pH} 5.5$, containing $5 \mathrm{mM}$ glutathione and
$2 \mathrm{mM}$ EDTA. The samples were incubated at $37^{\circ} \mathrm{C}$ with the enzymes for 5 days. Silk nanoparticle morphology and particle size distribution were then studied by scanning electron microscopy. Zeta potential measurements were performed as detailed below.

Nanoparticle Mass Loss. Native and PEGylated silk nanoparticles were exposed to model enzymes and incubated at $37{ }^{\circ} \mathrm{C}$ in $2 \mathrm{~mL}$ Eppendorf tubes. The controls were (i) native silk particles in water, (ii) PEGylated silk nanoparticles in water, and (iii) respective model enzymes in water; the control samples were treated identically to the respective enzyme-treated samples. All Eppendorf tubes were weighed before adding the sample (W1). On treatment days $1,3,5,10$, and 20 , the samples were centrifuged at $16000 \mathrm{~g}$ for $40 \mathrm{~min}$. The pellet and supernatant were collected, frozen, and lyophilized. The tubes containing freeze-dried pellets were weighed (W2) to determine the nanoparticle mass remaining after the treatment using (eq 1) (silk nanoparticles in water served as the control; i.e., $100 \%$ weight).

$$
\% \text { mass remaining }=\frac{(\mathrm{W} 2-\mathrm{W} 1)}{\text { weight of control nanoparticles }} \times 100
$$

Particle Size and Zeta Potential. The changes in particle size and zeta potential were determined by dynamic light scattering (DLS, Zetasizer Nano-ZS Malvern Instrument, Worcestershire, U.K.) for native and PEGylated silk nanoparticles treated with and without enzymes for 1, 3, 5, 10, and 20 days. Refractive index values of 1.33 for ultrapure water and 1.60 for silk were used for computation of particle size.

Secondary Structure Measurement. Untreated and enzymetreated silk nanoparticles were centrifuged, washed with ultrapure water, frozen, and then freeze-dried. The samples were subjected to Raman and Fourier transform infrared (FTIR) spectroscopy to determine the secondary structure of silk. Raman spectra measurements were performed using a Raman XploraA microscope (Horiba Jobin Yvon, Villeneuve d'Ascq, France). The 50X objective lens was used, and the laser wavelength was $532 \mathrm{~nm}$. The spectrum was recorded between 50 and $3500 \mathrm{~cm}^{-1}$, with 2 accumulations for $20 \mathrm{~s}$ per acquisition using a grating with 1200 grooves $\mathrm{mm}^{-1}$. FTIR was carried out using a TENSOR II FTIR spectrometer (Bruker Optik $\mathrm{GmbH}$, Ettlingen, Germany). Each measurement was run for 128 scans at $4 \mathrm{~cm}^{-1}$ resolution over the wavenumber range of 400 to 4000 $\mathrm{cm}^{-1}$. OriginPro 9.2 software was used to correct baselines and peak fits at the amide I region $\left(1595-1705 \mathrm{~cm}^{-1}\right)$. Briefly, the amide I region was identified and deconvoluted: ${ }^{24} 1605-1615 \mathrm{~cm}^{-1}$ as side chain/aggregated strands, $1616-1637 \mathrm{~cm}^{-1}$ and $1697-1703 \mathrm{~cm}^{-1}$ as $\beta$-sheet structure, $1638-1655 \mathrm{~cm}^{-1}$ as random coil structure, $1656-$ $1662 \mathrm{~cm}^{-1}$ as $\alpha$-helical bands, and $1663-1696 \mathrm{~cm}^{-1}$ as $\beta$-turns. The second derivative was applied at the amide I region for peak finding. Gaussian line shapes were used for curve fitting. Overfitting of the data was avoided by fixing the peak full width at half-maximum at $10 \mathrm{~cm}^{-1}$.

Scanning Electron Microscopy. The morphology of native and PEGylated silk nanoparticles before and after enzyme treatment was imaged by scanning electron microscopy (SEM) using a FE-SEM SU6600 instrument (Hitachi High Technologies, Krefeld, Germany) at $5 \mathrm{kV}$. Samples were pipetted onto a silicon wafer and lyophilized overnight. The specimens treated with model enzyme were coated with carbon using a vacuum coater (Polaron Division E6100, Bio-Rad, Birmingham, UK), while the specimens of ex vivo lysosomal-treated nanoparticles were sputter-coated with $15 \mathrm{~nm}$ of gold using an ACE200 low vacuum sputter coater (Leica Microsystems, Wetzlar, Germany). The subsequent SEM images were analyzed using Image v1.50i software (National Institutes of Health, Bethesda, MD, U.S.A.).

Statistical Analyses. Data were analyzed using GraphPad Prism 7.0 (GraphPad Software, La Jolla, CA, U.S.A.). Multiple samples were evaluated by one-way analysis of variance (ANOVA) followed by Bonferroni's multiple comparison post hoc test. An asterisk denotes statistical significance as follows: $* P<0.05, * * P<0.01, * * * P<0.001$. All data are presented as mean values \pm standard deviation (SD), and the number of independent experiments $(n)$ is noted in each figure legend. 

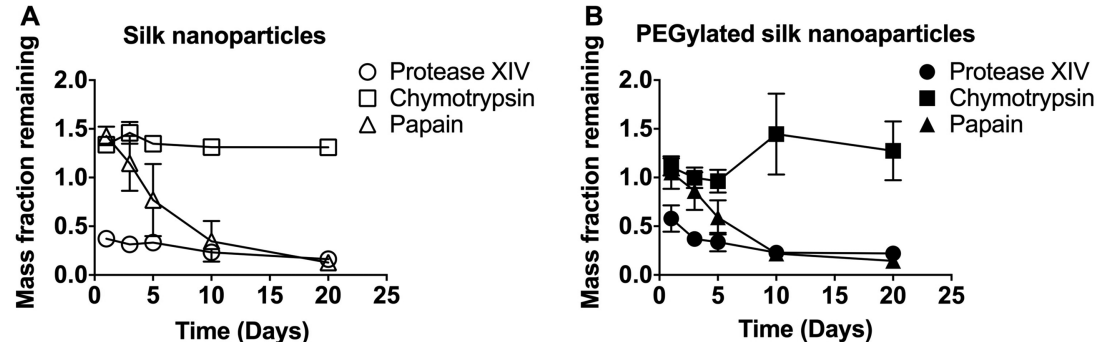

Figure 1. Nanoparticle mass loss after enzyme treatment of native and PEGylated silk nanoparticles. (A) The native silk nanoparticles and (B) PEGylated silk nanoparticles were treated with the respective enzymes and the remaining mass of nanoparticles over 20 days was measured. Data are from three independent experiments $(n=3) \pm \mathrm{SD}$; error bars are hidden within the plot symbols when not visible.
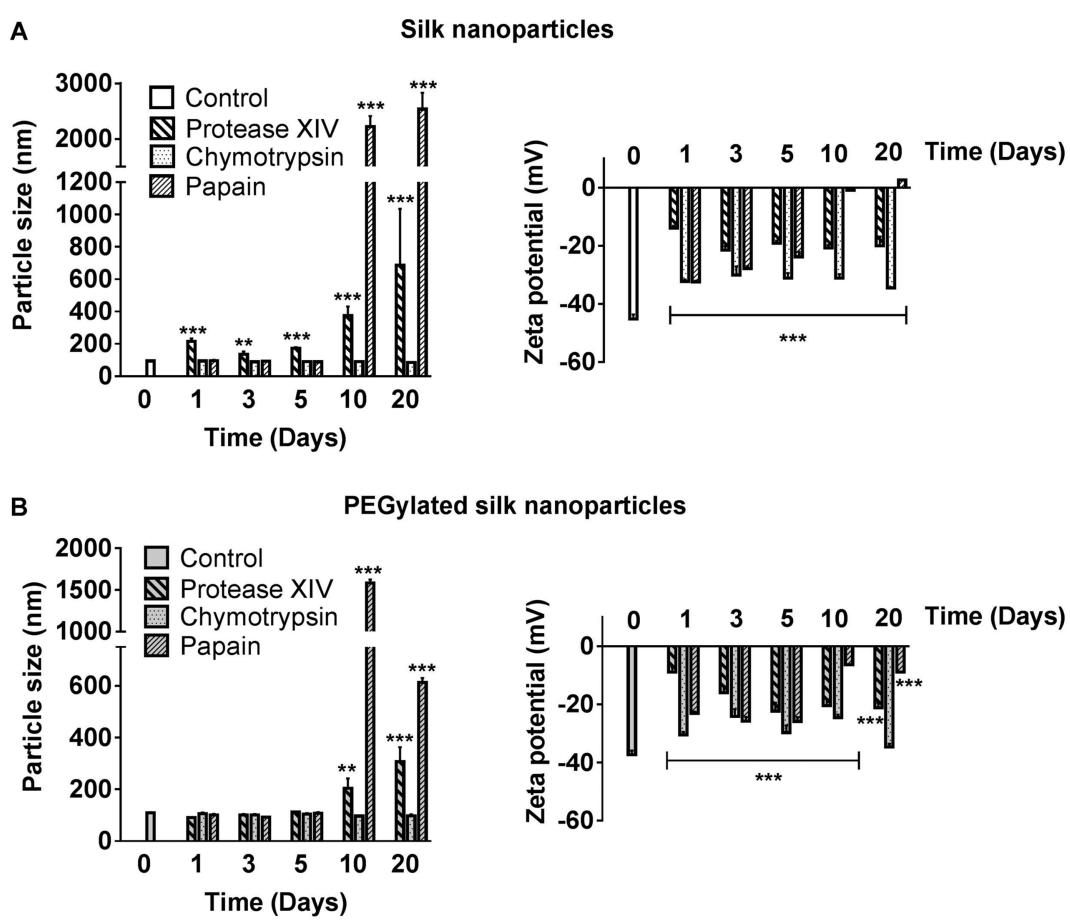

Figure 2. Particle size and zeta potential measurement of native and PEGylated silk nanoparticles following exposure to enzymes. Shifts in particle size and zeta potential of enzyme-treated (A) native silk and (B) PEGylated silk nanoparticles over the 20-day treatment cycle at $37{ }^{\circ} \mathrm{C}$. Data from three independent experiments $(n=3) \pm$ standard error of the mean; error bars are hidden in the bars when not visible.

\section{RESULTS}

Nanoparticle Mass Loss in Response to Enzymes. The mass of native and PEGylated silk nanoparticles exposed to protease XIV dropped rapidly to $40 \%$ and $60 \%$, respectively, of the original mass within 1 day. The degradation rate subsequently slowed after the 3-day treatment cycle. The mass loss of native and PEGylated silk nanoparticles treated with papain gradually decreased from day 1 to day 5 , resulting in a loss of more than $50 \%$ after 10 days of treatment. By contrast, no significant change was noted in the mass of the native or PEGylated silk nanoparticles after $\alpha$-chymotrypsin treatment (Figure 1).

Impact of Enzymes on Particle Size and Zeta Potential Changes. The particle size and zeta potential of control native silk nanoparticles were $94.44 \mathrm{~nm} \pm 3.03$ and $-45.2 \mathrm{mV} \pm 1.6$, respectively, whereas the particle size and zeta potential of the control PEGylated silk nanoparticles were $108.5 \mathrm{~nm} \pm 3.72$ and $-37.3 \mathrm{mV} \pm 1.4$, respectively. The particle size increased over the 20-day treatment cycle for the native and PEGylated silk nanoparticles treated with protease XIV (Figure 2). The negative zeta potentials for silk nanoparticles were shifted toward a less negative value over the treatment period (Figure 2). The size of the silk nanoparticles exposed to papain significantly increased and had reached 2.2 and $1.5 \mu \mathrm{m}$ for native and PEGylated silk nanoparticles, respectively, by day 10 (Figure 2). The zeta potential of silk nanoparticles treated with papain was considerably shifted toward a more neutral value after the 10-day treatment cycle. By contrast, no change was noted in the size or surface charge of the nanoparticles exposed to chymotrypsin (Figure 2A,C).

Effect of Proteolytic Enzymes on the Secondary Structure of Silk. The secondary structure of native and PEGylated silk nanoparticles before and after enzyme exposure was analyzed by FTIR and Raman spectroscopy (Figure 3 and Figure 4). The Raman bands at 1665 and $1229 \mathrm{~cm}^{-1}$ represent $\beta$-sheet structure in the amide I and amide III regions, respectively. The two bands at 1104 and $1084 \mathrm{~cm}^{-1}$ are due to alanine in coils/helix and $\beta$-sheet conformations, respectively. ${ }^{25}$ The Raman spectra showed similar results for both native and PEGylated silk nanoparticles treated with model enzymes. The amide I $\left(1665 \mathrm{~cm}^{-1}\right)$ and amide III $\left(1229 \mathrm{~cm}^{-1}\right)$ region of the nanoparticles did not change following enzyme treatment. 

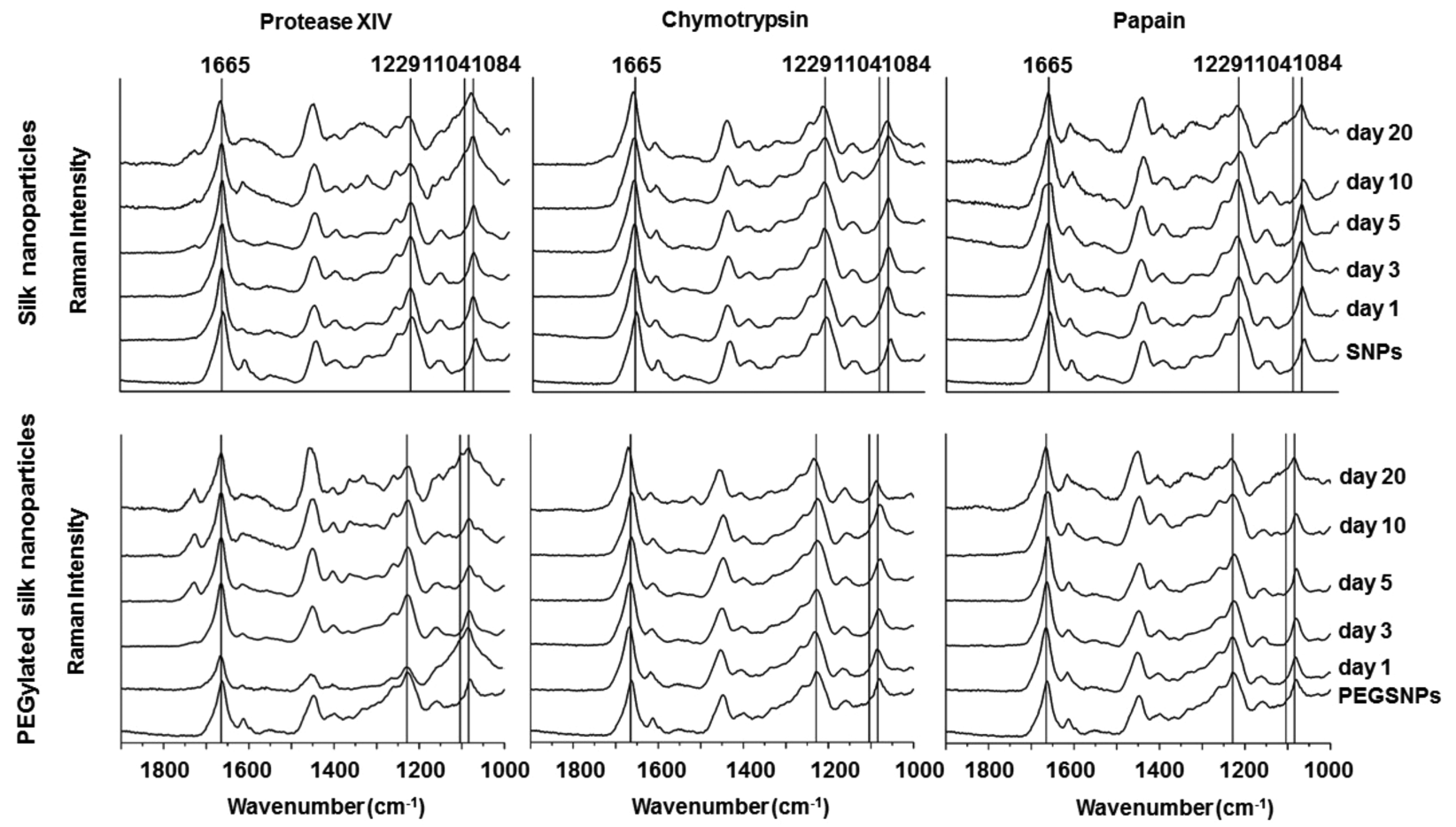

Figure 3. Raman spectra of native and PEGylated silk nanoparticles after enzyme degradation. The lines in the Raman spectra at 1665,1229 and $1084 \mathrm{~cm}^{-1}$ represent $\beta$-sheets, whereas $1104 \mathrm{~cm}^{-1}$ represents the amorphous segments.
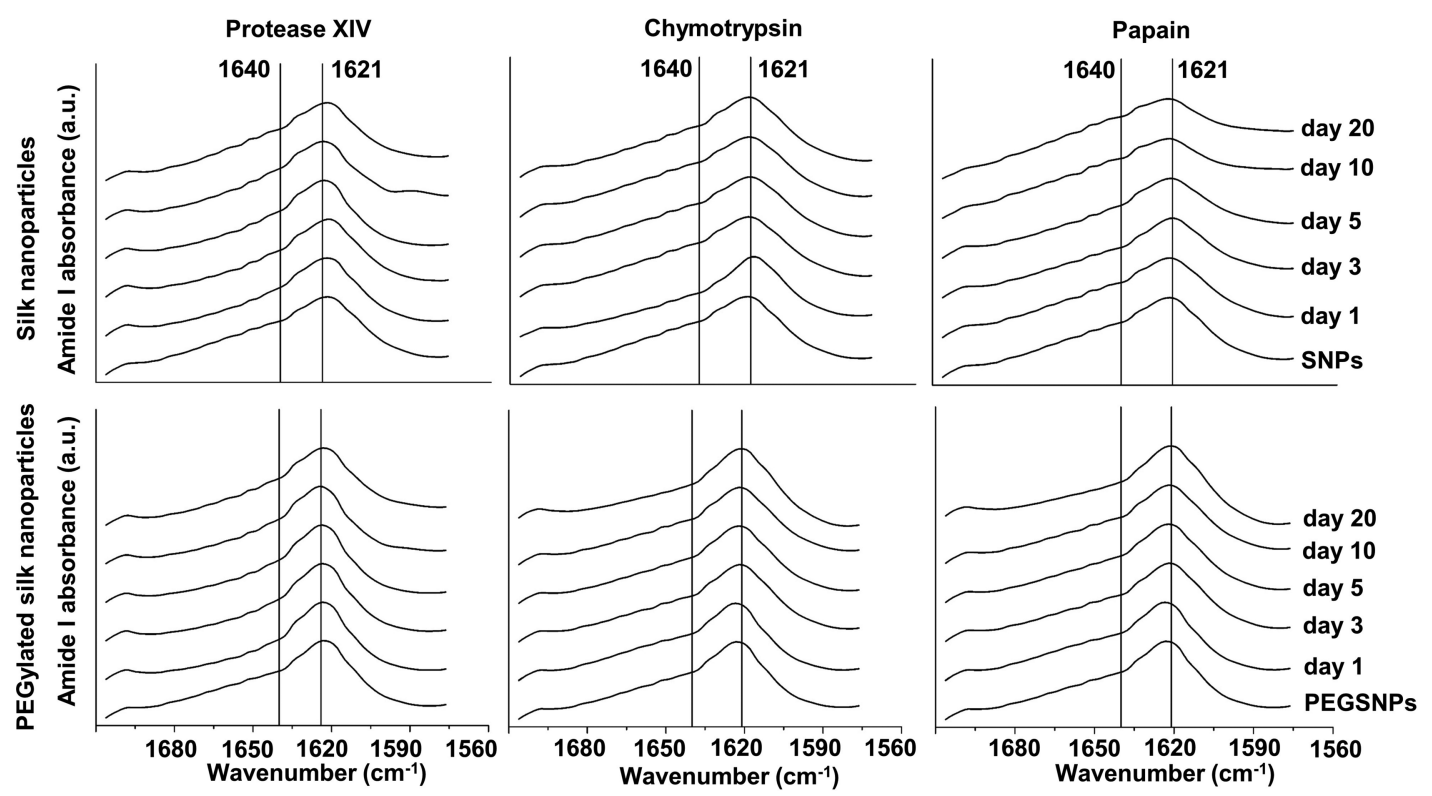

Figure 4. Determination of FTIR absorbance spectra of the amide I region of enzyme-treated native and PEGylated silk nanoparticles over time. The lines mark the absorbance band at 1621 and $1640 \mathrm{~cm}^{-1}$, representing antiparallel $\beta$-sheets and random coils/helixes, respectively.

However, silk nanoparticles treated with protease XIV and papain showed peak broadening at 1104 and $1084 \mathrm{~cm}^{-1}$ over the 20-day treatment cycle (Figure 3).

For FTIR analysis, the amide I bands at 1621 and $1640 \mathrm{~cm}^{-1}$ are attributed to $\beta$-sheet and amorphous structures, respectively. ${ }^{24}$ The amide I region of the native and PEGylated silk nanoparticles did not change over the 20-day enzyme treatment cycle, when compared with the control (Figure 4).

Fourier self-deconvolution (FSD) was applied to extract the secondary structure content (\%) from the FTIR spectra of the enzyme-exposed silk nanoparticles (Figure 4). The percentage contribution to the secondary conformation of the structural elements was derived from the area under the individual deconvoluted peaks (Figure S1). The observed changes were similar for both native and PEGylated silk nanoparticles. However, marked differences were evident, depending on the enzymes tested. Protease XIV reduced random coil $/ \alpha$-helix structure and $\beta$-turns, which resulted in a proportional increase in $\beta$-sheet structure of the silk nanoparticles (Figure 5). The increase in $\beta$-sheets was attributed to the increase in intermolecular $\beta$-sheet content over the 20-day treatment cycle (Figure S2). Papain decreased the overall $\beta$-sheet content 


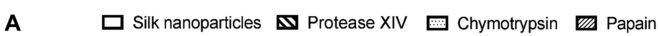
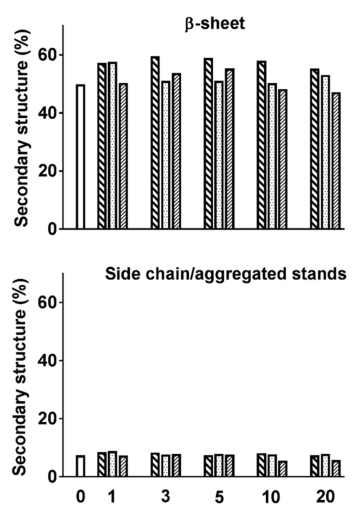
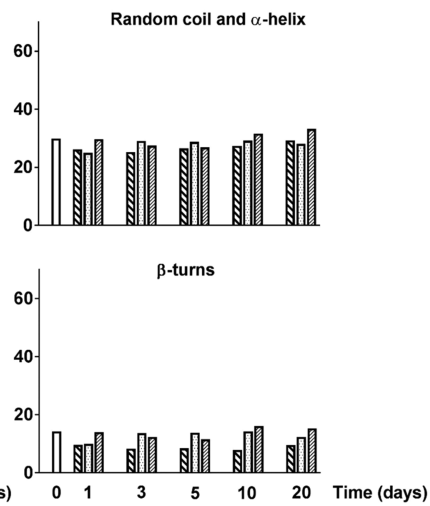

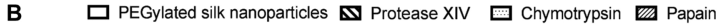
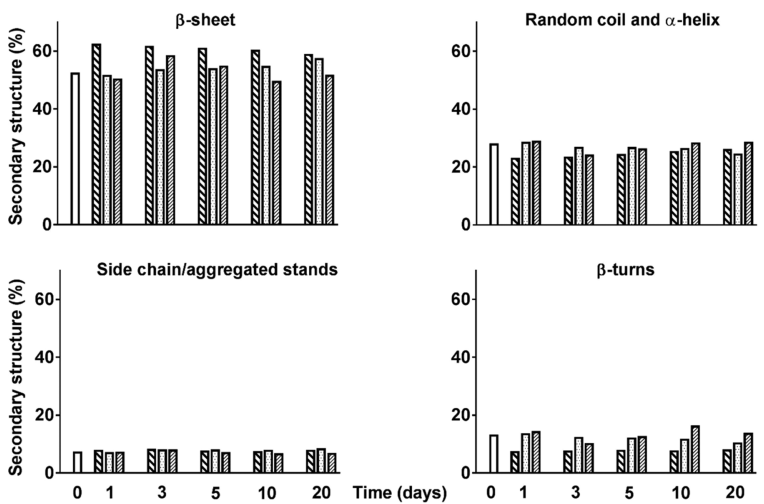

Figure 5. Quantification of the secondary structure (\%) of enzyme-treated native and PEGylated silk nanoparticles over time. Secondary structures: $\beta$-sheets, random coil, and $\alpha$-helix, side chain/aggregated stands and $\beta$-turns of (A) silk nanoparticles and (B) PEGylated silk nanoparticles over the 20-day enzyme treatment cycle.

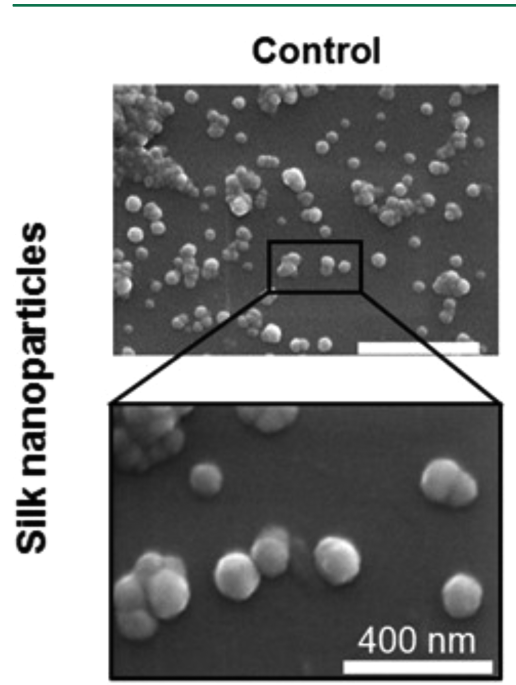

Control

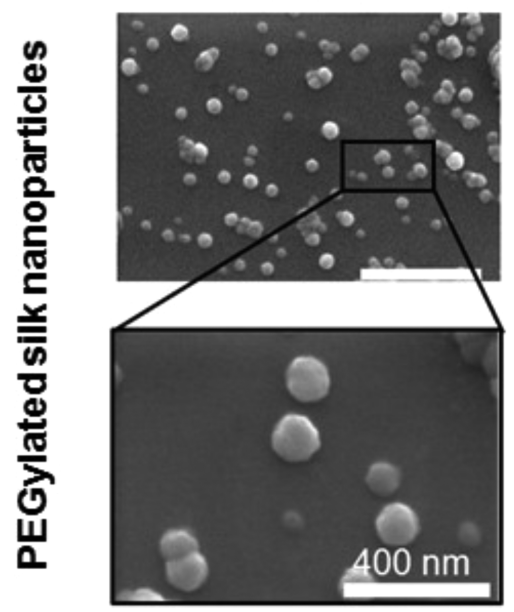

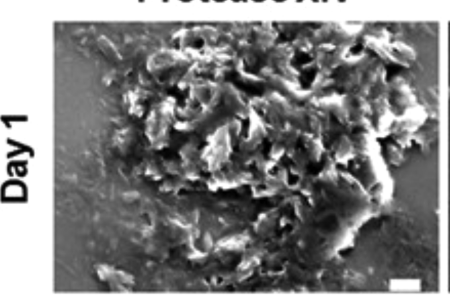
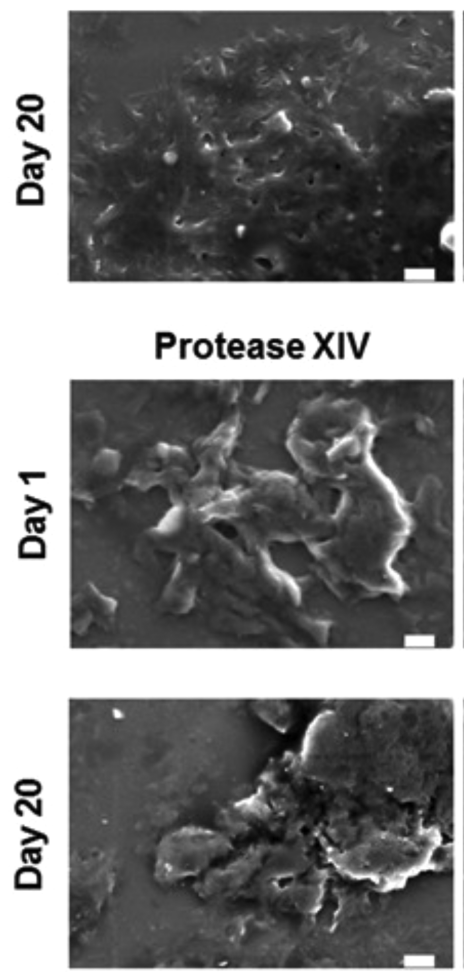

\section{$\alpha-$ Chymotrypsin}
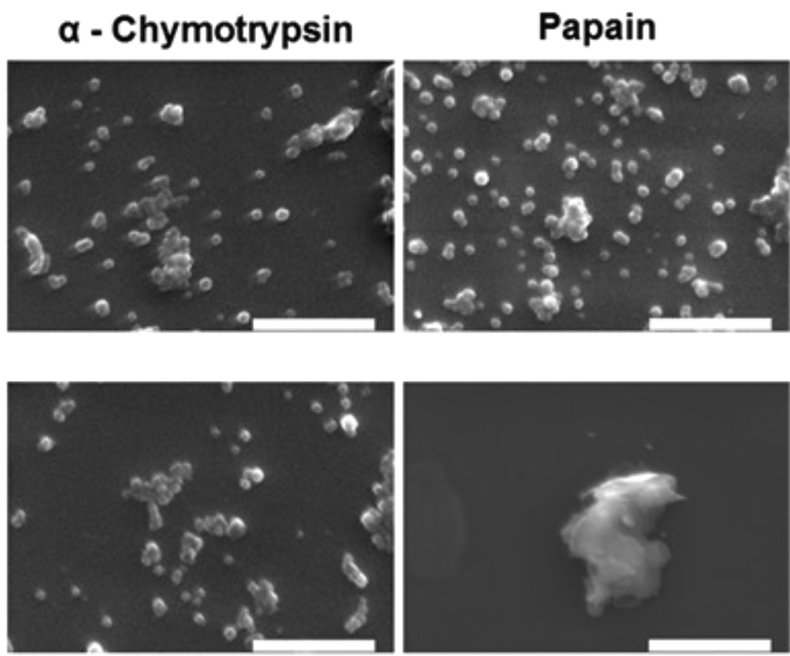

$\alpha-$ Chymotrypsin
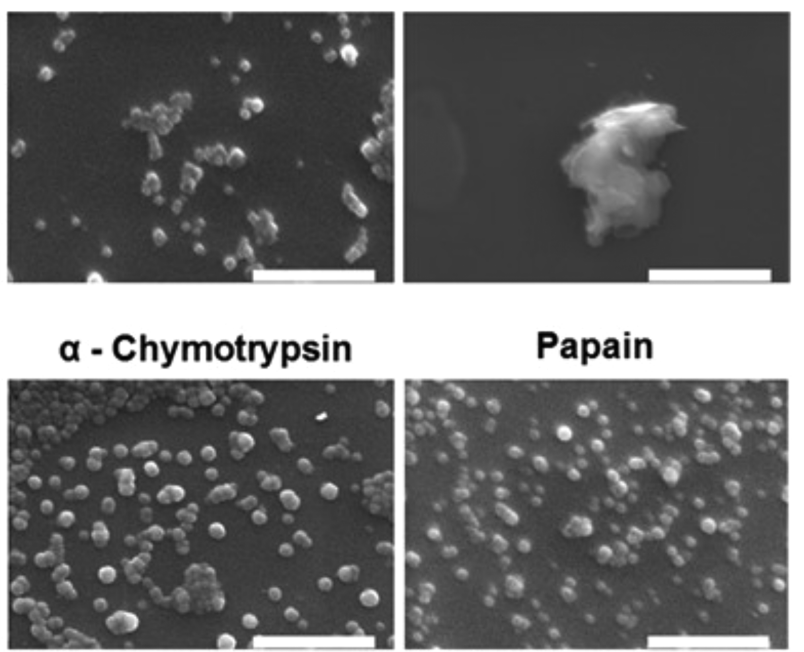

Papain
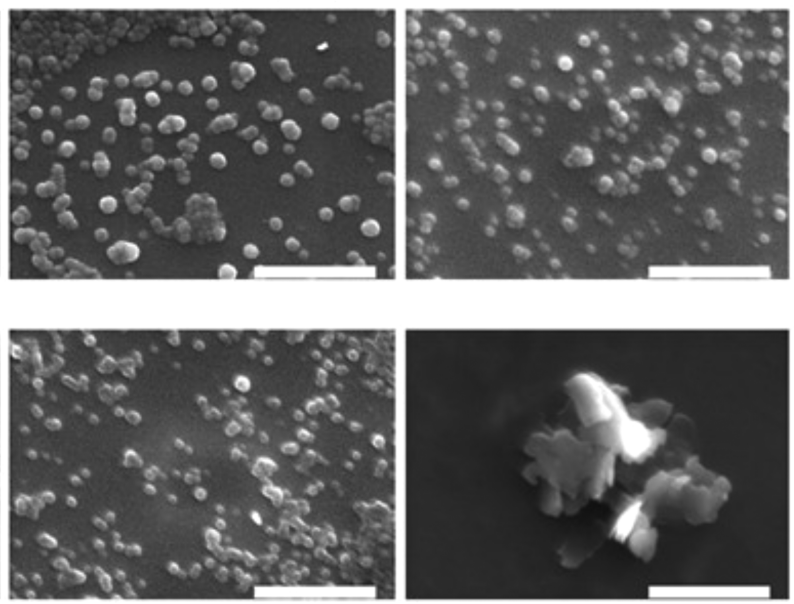

Figure 6. Scanning electron microscopy (SEM) images of native and PEGylated silk nanoparticles after 20 days of treatment with or without enzymes (scale bar $=1 \mu \mathrm{m})$.

after 10 days of enzyme treatment due to a reduction in the content of intermolecular $\beta$-sheets within the silk nanoparticles (Figure S2). Consequently, a proportional increase was observed in the random coil $/ \alpha$-helix structure. Alphachymotrypsin treatment decreased the random coil and $\alpha$ - helix content of silk nanoparticles at day 1 , but the content was restored to control values by day 3 and was maintained until day 20 (Figure 5). By contrast, $\alpha$-chymotrypsin did not affect the secondary structure of PEGylated silk nanoparticles over the 20-day treatment cycle (Figure 5). 
A
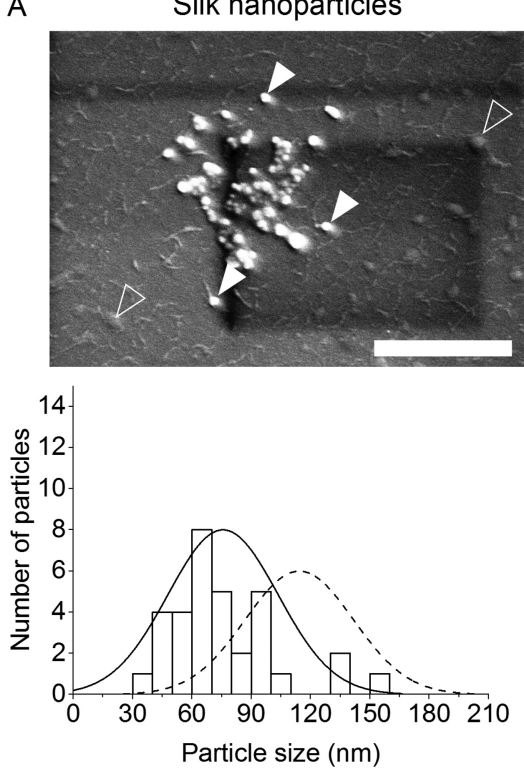

Time (days)

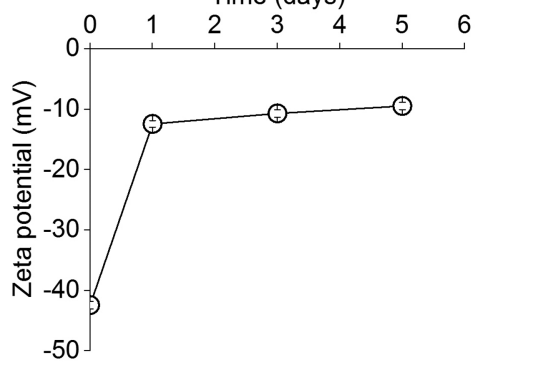

B PEGylated silk nanoparticles
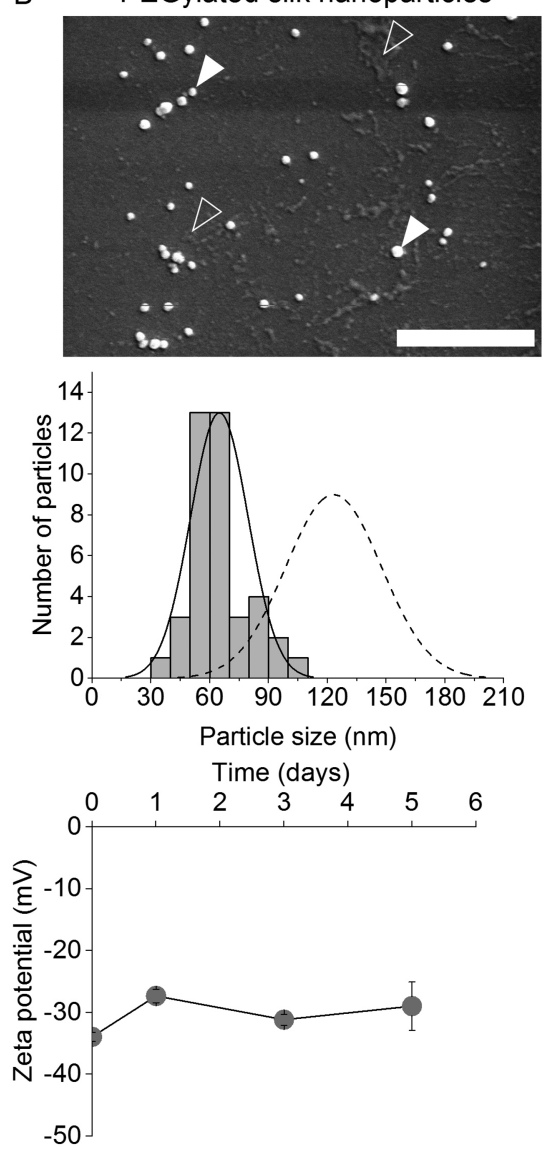

Figure 7. Qualitative and quantitative analysis of native and PEGylated silk nanoparticles following lysosomal enzyme exposure. Scanning electron microscopy (SEM) images, particle size distribution, and zeta potential of (A) native silk nanoparticles and (B) PEGylated silk nanoparticles after a 5-day exposure to ex vivo lysosomal enzymes (scale bar $=1 \mu \mathrm{m}$ ). For SEM images closed arrows denote the remaining nanoparticles and open arrows denote degradation products. The normal distributions show the particle size distribution of nanoparticles (dashed line) and enzyme-treated nanoparticles (solid line).

Morphology Changes of Nanoparticles. Electron microscopy studies indicated that native and PEGylated silk nanoparticles were spherical particles in the nanometer size range (100 to $120 \mathrm{~nm}$ ) (Figure 6). The morphological changes were similar for both native and PEGylated silk nanoparticles following enzyme treatment. Nanoparticles exposed to protease XIV for 1 day aggregated and appeared swollen, porous, and irregularly shaped. The continuous degradation of silk by protease XIV was accompanied by a change to a more compact morphology. Nanoparticles treated with papain remained within the nanometer size range and retained a spherical shape after 1 day of treatment; however, the particles were significantly degraded and were closely packed into micrometer sized particles without pores after the 20-day enzyme exposure. By contrast, nanoparticles exposed to $\alpha$-chymotrypsin did not change in shape or size over the 20-day treatment cycle (Figure 6).

Characterization of the Nanoparticles Exposed to Isolated Lysosomal Enzymes. The morphological changes of native and PEGylated silk nanoparticles were investigated by SEM following a 5-day ex vivo lysosomal enzyme treatment. The particle size of enzyme-degraded silk nanoparticles was heterogeneous and averaged $75.7 \pm 27.9 \mathrm{~nm}$ (Figure 7A). The silk nanoparticles aggregated after enzyme exposure and showed irregular shapes; evidence of residual material was visible on the mica surface (Figure $7 \mathrm{~A}$ open arrow). The zeta potential of native silk nanoparticles exposed to lysosomal enzymes dropped substantially to a near-neutral value after 1 day of treatment (Figure 7A). By contrast, the particle size distribution remained more homogeneous $(64.9 \pm 14.7 \mathrm{~nm})$ with only small changes to the zeta potential for the enzymetreated PEGylated silk nanoparticles, which showed no/little aggregation and less residual material overall on the surface (Figure 7B).

\section{DISCUSSION}

Nanoparticles designed for lysosomotropic drug delivery need to successfully navigate from the injection site to their final destination (i.e., the lysosomes) to elicit the desired therapeutic response. ${ }^{5}$ Silk nanoparticles are readily trafficked in vitro to lysosomes, where the acidic environment and proteolytic enzymes trigger drug release. ${ }^{15}$ However, the impact of the lysosomal environment on the fate and material properties of native and PEGylated silk nanoparticles is unknown. The accumulation of PEGylated nanoparticles in lysosomes imposes a potential risk of evoking a "lysosomal storage disease-like" response, when the material destined for lysosomal degradation is not degraded at a sufficient rate but instead accrues and perturbs organelle function. ${ }^{26,27}$

Clinical experience with nonbiodegradable polymers, such as $\mathrm{N}$-(2-hydroxypropyl)methacrylamide (HPMA) ${ }^{28}$ and polyethylene glycol (PEG), ${ }^{29}$ has been encouraging. Nonetheless, 
A

$\mathrm{N}$-terminus

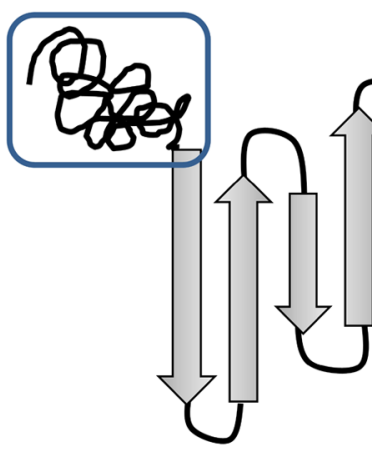

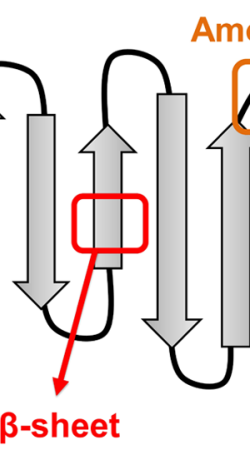

Heavy chain
Amorphous

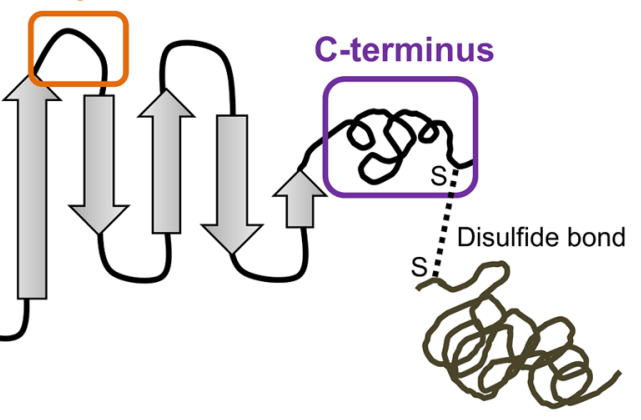

Light chain

B

$\mathrm{N}$-terminus

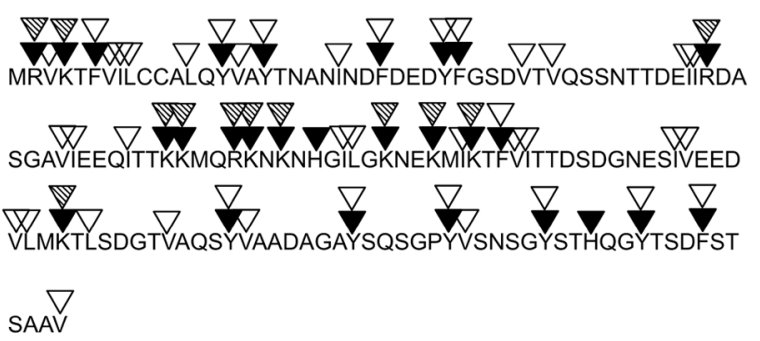

$\beta$-sheet

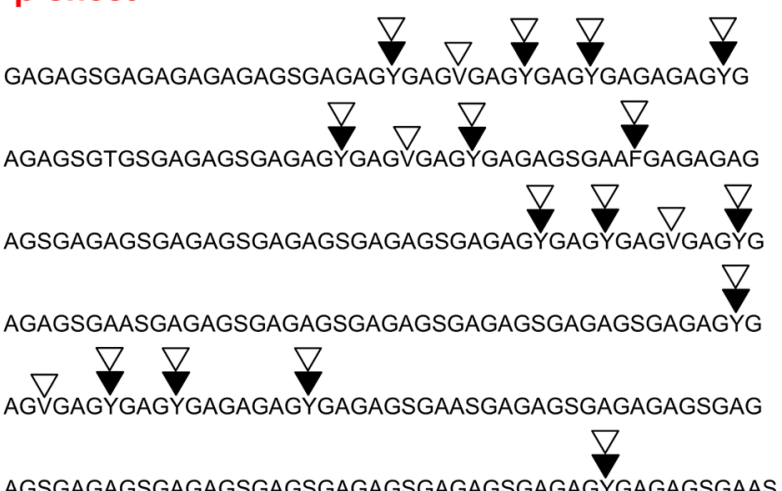

C

\begin{tabular}{llcccccc}
\hline & & \multicolumn{5}{c}{ Number of cleavage sites } \\
\cline { 3 - 8 } \multicolumn{1}{c}{ Enzymes } & Cleavage sites & Heavy chain & N-terminus & B-sheet & Amorphous & C-terminus Light chain \\
Protease XIV & Typ, Phe,Trp, His, Lys, Arg & 348 & 27 & 222 & 84 & 15 & 41 \\
Chymotrypsin & Typ, Phe,Trp, Val, Ile, Leu & 434 & 41 & 291 & 88 & 14 & 81 \\
Papain & Lys, Arg & 26 & 12 & 0 & 4 & 10 & 15 \\
\hline
\end{tabular}

Figure 8. B. mori schematic and cleavage sites of proteolytic enzymes of the silk amino acid sequence. (A) Two dimensional schematic of silk structure including the heavy chain (i.e., $\mathrm{N}$-terminus, crystalline $\beta$-sheets, amorphous, and C-terminus) and light chain. (B) Enzymatic specificities of proteolytic enzymes for the silk sequences. The silk amino acid sequences was extracted from Prot/TrEMBL accession numbers P05790 and P21828. (C) Number of cleavage sites of proteolytic enzymes on different silk domains.

the safety window for HPMA- and PEG-based nanomedicines depends on a multitude of factors, including (but not limited to) dosing frequency (i.e., chronic versus acute), polymer dose,

\section{Amorphous}

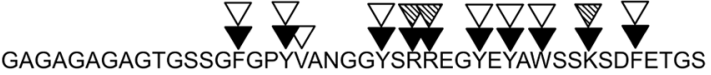

C-terminus

$\nabla$
$\nabla S Y G A G R G$ Q
$\nabla$

W

VVKFRALPCVNC

\section{Light chain}

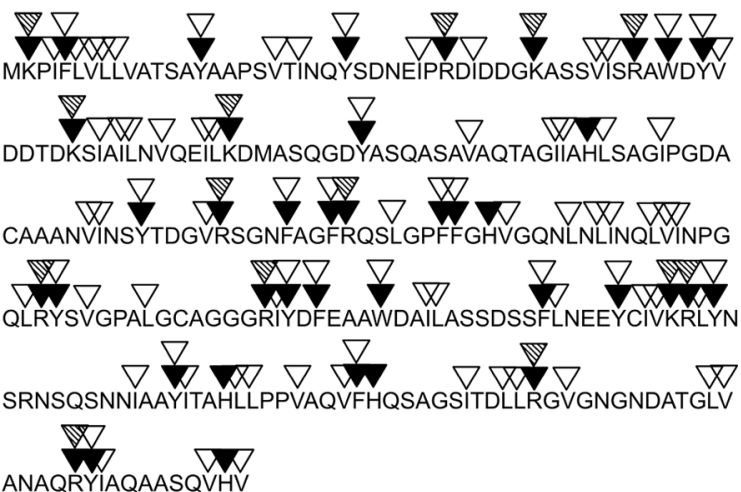


biopharmaceuticals have shown evidence of (transient) vacuolation, primarily in phagocytic cells. ${ }^{30}$ Furthermore, metabolic reprogramming of macrophages with (silk) nanoparticles has recently been reported. ${ }^{31}$

Silk has a remarkable clinical track record, and it is degraded by proteolytic enzymes, ${ }^{32}$ but the response to enzymes when silk is in nanoparticle form is unknown. Simply assuming that silk nanoparticles will behave similarly to other macro-sized silk formats is not scientifically rigorous. ${ }^{5}$ Furthermore, material performance is context specific and thus requires dedicated assessments. The present study represents the first inroads into the assessment of silk nanoparticle degradation by proteolytic enzymes.

The proteolytic susceptibility of both native and PEGylated silk nanoparticles was determined by assessing the mass loss in response to enzyme exposure. All the silk nanoparticle responses showed a similar rank order (protease XIV > papain $\gg \alpha$-chymotrypsin) (Figure 1). Previous studies with silk films and hydrogels also demonstrated that silk degradation was significantly faster with protease XIV than with $\alpha$-chymotrypsin. ${ }^{19}$ The silk sequence alignment indicates $434 \alpha$ chymotrypsin cleavage sites in the silk heavy chain and 81 in the light chain, and 348 and 41 Protease XIV cleavage sites in the heavy and light chains, respectively ${ }^{19}$ (Figure 8, Figure S5). Thus, the differences in silk degradation are not governed only by the number of cleavage sites but are critically dependent on enzyme accessibility, the silk format, and the secondary structure of the silk.

In the current study, degradation was slower at the early time points (i.e., day 1 enzyme exposure and the resulting mass loss and particle size) for PEGylated silk nanoparticles than for native silk nanoparticles for all the tested enzymes (Figure 1 and 2). This relatively lower degradation rate for PEGylated silk probably reflects the ability of PEG to shield the silk surface and thus hinder the access of the proteolytic enzymes. This protective effect concurs with indirect observations in single breast cancer cells, ${ }^{15}$ where a slower therapeutic payload release was observed from PEGylated silk nanoparticles than from native silk nanoparticles, suggesting a reduced proteolytic degradation.

We also measured the particle size and charge in response to enzyme treatment. We observed significant swelling of silk nanoparticles, as reported for other protein-based nanoparticles (e.g., human serum albumin). ${ }^{33,34}$ We therefore speculate that proteolytic enzymes disturbed the silk packing geometry permitting greater water ingress that resulted in particle swelling. Simultaneously, degradation reduced surface charges (Figure 2) enabling degradation products to loosely accumulate on the remaining particle surface (Figure 6). Increases in particle size were readily observed from day 10 onward, and these changes were particularly evident for the papain-treated silk nanoparticles (Figure 2). Papain exposure progressively changed the negative zeta potential of silk nanoparticles toward more positive values. This was particularly evident for the native silk nanoparticles and less so for the PEGylated ones, which suggested that PEGylation could provide steric hindrance and protection against proteolytic degradation (Figure S6). Silk sequence alignment showed that 26 sites in the silk heavy chain and 15 sites in the light chain are susceptible to cleavage by papain (Figure 8 and Figure S5). Papain cleaves arginines and lysines of the silk sequence; the latter one is also exploited for PEGylation in addition to histidine and tyrosine. ${ }^{5}$ Papain cleavage of lysines and arginines would be expected to lead to a net loss of positive charge. Thus, the observed overall loss of the negative zeta potential is counterintuitive and requires more work to explain the experimental data. Similar considerations apply for protease XIV (Figure 2). By contrast, $\alpha$-chymotrypsin treatment did not change the particle size or zeta potential of either the native or the PEGylated silk nanoparticles over the 20 day treatment cycle, as reflected by the maintenance of a consistent nanoparticle mass (Figure 1). Previous studies using silk films and hydrogels also reported minimal degradation by $\alpha$ chymotrypsin. ${ }^{19}$

We used Raman and FTIR spectroscopy to obtain a better understanding of the changes in native and PEGylated silk nanoparticles following enzyme treatment. The amide I band in FTIR and the amide I and III bands in Raman are well-suited for assigning secondary structures to proteins, ${ }^{35}$ and they are also widely applied to silk. ${ }^{36}$ The typical wavenumbers in Raman spectroscopy for protein secondary structure are 1662$1655,1272-1264$, and $1104 \mathrm{~cm}^{-1}$ for random coils $/ \alpha$-helixes and $1674-1672,1242-1227$, and $1084 \mathrm{~cm}^{-1}$ for $\beta$-sheets. ${ }^{25,37}$ The Raman spectra of native and PEGylated silk nanoparticles showed signal intensities at 1665,1229 , and $1084 \mathrm{~cm}^{-1}$, which indicated a $\beta$-sheet conformation for silk (Figure 3). No changes were evident in the amide I spectra of the enzymetreated nanoparticles due to the lower sensitivity of the Raman versus the FTIR spectra. ${ }^{38}$ However, the band at 1104 and $1084 \mathrm{~cm}^{-1}$ was used to analyze secondary structure changes of silk nanoparticles. The bandwidth in this region became progressively broader for silk nanoparticles exposed to protease XIV and papain, from 5 days onward, indicating that these enzymes digested $\beta$-sheet sequences.

The FTIR measurements confirmed that both native and PEGylated silk nanoparticles had high $\beta$-sheet contents (i.e., high amide I absorbance at $1621 \mathrm{~cm}^{-1}$ ). The overall silk FTIR spectra bands did not show visible changes following enzyme exposure (Figure 4), so Fourier self-deconvolution (FSD) was applied to quantify the secondary structure. ${ }^{24}$ Protease XIV emerged as the most powerful proteolytic enzyme, as it caused substantial changes in the secondary structure of both native and PEGylated silk nanoparticles. Protease XIV can cleave many amino acids (e.g., histidine, phenylalanine, tryptophan, tyrosine, lysine, and arginine) that are found in the crystalline (222 sites) and amorphous regions (84 sites) (Figure 8). Overall, protease XIV has a low specificity, which facilitates its degradation of the crystalline and amorphous regions of silk. ${ }^{19}$ Conceivably, protease XIV first degraded the surface residues, which are expected to be present as random coils $/ \alpha$-helixes, followed by $\beta$-sheets, which are found in the core of the silk nanoparticle.

We also included papain in our study because it is a cysteine protease enzyme that mimics the activity of lysosomal enzymes. $^{22,39}$ It can hydrolyze peptide bonds formed by the carboxyl groups of lysine and arginine and adjacent amino acid residues. ${ }^{22,39}$ These lysine and arginine amino acid residues are found both in the heavy and light silk chain. However, they are not found in the crystalline domains, but four sites are present in the amorphous segments of the silk heavy chain and 22 sites in the $\mathrm{C}$ - and $\mathrm{N}$-termini, as well as 15 sites in the silk light chain (Figure 8). By contrast, secondary structure analysis of silk nanoparticles treated with $\alpha$-chymotrypsin showed no evidence of silk structural changes in either the crystalline or the random coil $/ \alpha$-helix structures. These observations were supported by morphological studies and the absence of loss of mass over the 
20-day treatment cycle. The resistance of silk to $\alpha$ chymotrypsin digestion over short time frames has also been reported by others. ${ }^{19}$

We next examined the morphological changes following enzymatic degradation of native and PEGylated silk nanoparticles (Figure 6). Protease XIV effectively digested both native and PEGylated silk nanoparticles and elicited gross changes in morphology within $24 \mathrm{~h}$. A slower, but similar, degradation pattern was observed following the papain treatment. The morphologies observed in the present study differed from those previously reported for silk films treated with protease XIV. ${ }^{40,41}$ Our experience with silk films suggests that the silk format (i.e., nanoparticle versus film) as well as the processing parameters (e.g., water annealing, slow drying, and stretching) affects the degradation. ${ }^{40}$ The generation of nanofilaments (up to $10 \mathrm{~nm}$ thick and with a $10 \mu \mathrm{m}$ surface area $)^{41}$ has been reported following protease XIV treatment of silk crystals, but no nanofilaments were observed in the present study. We also did not observe any noticeable silk degradation in response to $\alpha$-chymotrypsin treatment. The SEM images confirmed that $\alpha$-chymotrypsin treatment had no detectable effect on the silk nanoparticle morphology (Figure 6).

Protease XIV is a useful model enzyme for studying the fundamental principles of silk degradation (and for direct comparison with many previous reports that typically use protease XIV). In the current study, we also included $\alpha$ chymotrypsin because it is a relevant mammalian enzyme (unlike protease XIV which is a nonmammalian enzyme) (see for discussion). However, silk nanoparticles are typically designed for lysosomotropic drug delivery; thus, the degradation behavior of silk nanoparticles in response to lysosomal enzymes is most relevant. We used the lysosomal model enzyme papain (discussed above and used at equivalent enzymatic units to permit direct comparisons), as well as lysosomes isolated from mammalian tissue. First, we isolated and extensively characterized our lysosomal preparation (see Supporting Information). The preliminary results from ex vivo lysosomal degradation studies showed that native and PEGylated silk nanoparticles were slowly degraded over the initial 5 days, as evidenced by a reduction in particle size, changes in surface charge as well as by the formation of visible degradation products (Figure 7). As expected, PEGylation was able to slow silk nanoparticle degradation and conserve surface charge; in contrast, native silk nanoparticles showed a reduction in surface charge already at day 1 . This was expected because model enzymes showed a similar trend (Figure 2). We note that high vacuum SEM images did not show obvious signs of particle swelling and we speculate that sample preparation for SEM imaging might be responsible for this. Technical limitations (e.g., the difficulty of keeping a constant $3.5 \mathrm{U}$ ratio of nanoparticles to enzymes while working with limited amounts of lysosomes, but also ensuring sufficient amounts of silk to permit zeta potential measurements as well as detection and visualization by SEM) precluded the extension of these degradation studies beyond the 5-day time point. However, the lysosome-like model enzyme, papain, ${ }^{22}$ also showed an initially slow silk nanoparticle degradation similar to that seen with the isolated enzymes; therefore, we speculate that silk nanoparticles would be fully degraded in lysosomes given longer exposure cycles.

\section{CONCLUSIONS}

The presence of surface PEGylation hindered enzyme accessibility and slowed silk degradation. Overall, silk nanoparticles showed a differential degradation behavior in response to proteolytic enzymes, including lysosome-like enzymes (rank order: protease XIV > papain $\gg \alpha$-chymotrypsin). Preliminary studies with isolated lysosomal enzymes support the notion that silk nanoparticles will be degraded within lysosomes. In summary, this study provides the first insight into the proteolytic susceptibility of silk nanoparticles within target cells, for example, cancer cells.

\section{ASSOCIATED CONTENT}

\section{S Supporting Information}

The Supporting Information is available free of charge on the ACS Publications website at DOI: 10.1021/acsbiomaterials.7b01021.

Fourier self-deconvolution absorbance spectra; $\beta$-sheet content (\%) of enzyme-treated native and PEGylated silk nanoparticles; relative specific activity (RSA) of $\mathrm{N}$-acetyl$\beta$-glucosaminidase (NAG) in subcellular fractions; enzyme activity $(\mathrm{U} / \mathrm{ml})$ of the combined lysosome-rich fractions upon various treatment conditions; physicochemical properties of (A) heavy chain and (B) light chain of silk before and after enzyme exposure; and schematic of PEGylated silk nanoparticles (PEG-SNPs) and cleavage sites by proteolytic enzymes (PDF)

\section{AUTHOR INFORMATION}

\section{Corresponding Author}

*Tel. +44 (0) 141548 2510. E-mail: philipp.seib@strath.ac.uk or philipp.seib@SeibLab.com.

\section{ORCID}

Blair F. Johnston: 0000-0001-9785-6822

F. Philipp Seib: 0000-0002-1955-1975

\section{Notes}

The authors declare no competing financial interest.

All data created during this research are openly available from the University of Strathclyde-Pure, at http://dx.doi.org/10. 15129/18b67297-5f27-4c5f-b170-8d0c21dfc656.

\section{ACKNOWLEDGMENTS}

The authors would like to thank Prof. Samir H. Mushrif (School of Chemical and Biomedical Engineering, Nanyang Technological University, Singapore) for mentoring T.W. and Dr. John Graham (Liverpool, UK) for insightful discussion relating to gradient centrifugation and lysosome isolation. This research was supported by a FP7-PEOPLE-2012-CIG MarieCurie Action Career Integration Grant 334134 within the seventh European Union Framework Program (F.P.S.). The authors would like to thank the International Strategic Partnership between University of Strathclyde and Nanyang Technological University, Singapore for funding this work. The authors would like to acknowledge that this work was carried out in part at the EPSRC Future Continuous Manufacturing and Advanced Crystallization (CMAC) Research Hub (EP/ P006965/1), supported by a U.K. Research Partnership Fund award from the Higher Education Funding Council for England (Grant HH13054). 


\section{REFERENCES}

(1) Seib, F. P.; Kaplan, D. L. Silk for Drug Delivery Applications: Opportunities and Challenges. Isr. J. Chem. 2013, 53, 756-766.

(2) Omenetto, F. G.; Kaplan, D. L. New Opportunities for an Ancient Material. Science 2010, 329 (5991), 528-531.

(3) Holland, C.; Terry, A. E.; Porter, D.; Vollrath, F. Natural and unnatural silks. Polymer 2007, 48 (12), 3388-3392.

(4) Jewell, M.; Daunch, W.; Bengtson, B.; Mortarino, E. The development of SERI ${ }^{\circledR}$ Surgical Scaffold, an engineered biological scaffold. Ann. N. Y. Acad. Sci. 2015, 1358 (1), 44-55.

(5) Seib, F. P. Silk nanoparticles-an emerging anticancer nanomedicine. AIMS Bioeng. 2017, 4 (2), 239-258.

(6) Werner, V.; Meinel, L. From silk spinning in insects and spiders to advanced silk fibroin drug delivery systems. Eur. J. Pharm. Biopharm. 2015, 97, 392-399.

(7) Seib, F. P. Silk hydrogels for drug and cell delivery. In Hydrogels: Design, Synthesis and Application in Drug Delivery and Regenerative Medicine; Singh, T. R. R., Laverty, G., Donnelly, R., Eds.; CRC Press: Boca Raton, FL, 2018; pp 208-227.

(8) Wongpinyochit, T.; Uhlmann, P.; Urquhart, A. J.; Seib, F. P. PEGylated Silk Nanoparticles for Anticancer Drug Delivery. Biomacromolecules 2015, 16 (11), 3712-3722.

(9) Maitz, M. F.; Sperling, C.; Wongpinyochit, T.; Herklotz, M.; Werner, C.; Seib, F. P. Biocompatibility assessment of silk nanoparticles: Hemocompatibility and internalization by human blood cells. Nanomedicine 2017, 13 (8), 2633-2642.

(10) Matsumura, Y.; Meada, H. A New Concept for Macromolecular Therapeutics in Cancer Chemotherapy: Mechanism of Tumoritropic Accumulation of Proteins and the Antitumor Agent Smancs. Cancer Res. 1986, 46, 6387-6392.

(11) Nakamura, H.; Jun, F.; Maeda, H. Development of nextgeneration macromolecular drugs based on the EPR effect: challenges and pitfalls. Expert Opin. Drug Delivery 2015, 12 (1), 53-64.

(12) Wilhelm, S.; Tavares, A. J.; Dai, Q.; Ohta, S.; Audet, J.; Dvorak, H. F.; Chan, W. C. W. Analysis of nanoparticle delivery to tumours. Nat. Rev. Mater. 2016, 1 (5), 16014.

(13) Natfji, A. A.; Ravishankar, D.; Osborn, H. M. I.; Greco, F. Parameters Affecting the Enhanced Permeability and Retention Effect: The Need for Patient Selection. J. Pharm. Sci. 2017, 106 (11), 31793187

(14) Seib, F. P.; Jones, G. T.; Rnjak-Kovacina, J.; Lin, Y.; Kaplan, D. L. $\mathrm{pH}$-Dependent anticancer drug release from silk nanoparticles. Adv. Healthcare Mater. 2013, 2 (12), 1606-11.

(15) Totten, J. D.; Wongpinyochit, T.; Seib, F. P. Silk nanoparticles: proof of lysosomotropic anticancer drug delivery at single-cell resolution. J. Drug Target. 2017, 25 (9-10), 865-872.

(16) Altman, G. H.; Diaz, F.; Jakuba, C.; Calabro, T.; Horan, R. L.; Chen, J.; Lu, H.; Richmond, J.; Kaplan, D. L. Silk-based biomaterials. Biomaterials 2003, 24 (3), 401-416.

(17) Meinel, L.; Hofmann, S.; Karageorgiou, V.; Kirker-Head, C.; McCool, J.; Gronowicz, G.; Zichner, L.; Langer, R.; Vunjak-Novakovic, G.; Kaplan, D. L. The inflammatory responses to silk films in vitro and in vivo. Biomaterials 2005, 26 (2), 147-155.

(18) Wang, Y.; Rudym, D. D.; Walsh, A.; Abrahamsen, L.; Kim, H. J.; Kim, H. S.; Kirker-Head, C.; Kaplan, D. L. In vivo degradation of three-dimensional silk fibroin scaffolds. Biomaterials 2008, 29 (2425), 3415-3428.

(19) Brown, J.; Lu, C. L.; Coburn, J.; Kaplan, D. L. Impact of silk biomaterial structure on proteolysis. Acta Biomater. 2015, 11 (1), 212-221.

(20) Rajkhowa, R.; Hu, X.; Tsuzuki, T.; Kaplan, D. L.; Wang, X. Structure and biodegradation mechanism of milled Bombyx mori silk particles. Biomacromolecules 2012, 13 (8), 2503-2512.

(21) Cao, Y.; Wang, B. Biodegradation of silk biomaterials. Int. J. Mol. Sci. 2009, 10 (4), 1514-1524.

(22) Stoka, V.; Turk, B.; Turk, V. Lysosomal cysteine proteases: Structural features and their role in apoptosis. IUBMB Life 2005, 57 (4-5), 347-353.
(23) Wongpinyochit, T.; Johnston, B. F.; Seib, F. P. Manufacture and Drug Delivery Applications of Silk Nanoparticles. J. Visualized Exp. 2016, 116, e54669.

(24) Hu, X.; Kaplan, D.; Cebe, P. Determining beta-sheet crystallinity in fibrous proteins by thermal analysis and infrared spectroscopy. Macromolecules 2006, 39, 6161-6170.

(25) Monti, P.; Taddei, P.; Freddi, G.; Asakura, T.; Tsukada, M. Raman spectroscopic characterization of Bombyx mori silk fibroin: Raman spectrum of Silk I. J. Raman Spectrosc. 2001, 32, 103-107.

(26) Duncan, R.; Richardson, S. C. W. Endocytosis and intracellular trafficking as gateways for nanomedicine delivery: Opportunities and challenges. Mol. Pharmaceutics 2012, 9 (9), 2380-2402.

(27) Appelqvist, H.; Wäster, P.; Kågedal, K.; Öllinger, K. The lysosome: From waste bag to potential therapeutic target. J. Mol. Cell Biol. 2013, 5 (4), 214-226.

(28) Duncan, R. Development of HPMA copolymer-anticancer conjugates: Clinical experience and lessons learnt. Adv. Drug Delivery Rev. 2009, 61 (13), 1131-1148.

(29) Ivens, I. A.; Achanzar, W.; Baumann, A.; Brändli-Baiocco, A.; Cavagnaro, J.; Dempster, M.; Depelchin, B. O.; Irizarry Rovira, A. R.; Dill-Morton, L.; Lane, J. H.; et al. PEGylated Biopharmaceuticals. Toxicol. Pathol. 2015, 43, 959-983.

(30) Turecek, P. L.; Bossard, M. J.; Schoetens, F.; Ivens, I. A. PEGylation of Biopharmaceuticals: A Review of Chemistry and Nonclinical Safety Information of Approved Drugs. J. Pharm. Sci. 2016, 105 (2), 460-475.

(31) Saborano, R.; Wongpinyochit, T.; Totten, J. D.; Johnston, B. F.; Seib, F. P.; Duarte, I. F. Metabolic Reprogramming of Macrophages Exposed to Silk, Poly(lactic-co-glycolic acid), and Silica Nanoparticles. Adv. Healthcare Mater. 2017, 6 (14), 1601240.

(32) Thurber, A. E.; Omenetto, F. G.; Kaplan, D. L. In vivo bioresponses to silk proteins. Biomaterials 2015, 71, 145-157.

(33) Magee, G. A.; Willmott, N.; Halbert, G. W. Development of a reproduceable in vitro method for assessing the biodegradation of protein microspheres. J. Controlled Release 1993, 25 (3), 241-248.

(34) Magee, G. A.; Halbert, G. W.; Wilmott, N. Effect of Process Variables on the in-Vitro Degradation of Protein Microspheres. J. Controlled Release 1995, 37, 11-19.

(35) Pelton, J. T.; McLean, L. R. Spectroscopic Methods for Analysis of Protein Secondary Structure. Anal. Biochem. 2000, 277 (2), 167176.

(36) Lefêvre, T.; Rousseau, M.-E.; Pézolet, M. Protein Secondary Structure and Orientation in Silk as Revealed by Raman Spectromicroscopy. Biophys. J. 2007, 92 (8), 2885-2895.

(37) Rygula, A.; Majzner, K.; Marzec, K. M.; Kaczor, A.; Pilarczyk, M.; Baranska, M. Raman spectroscopy of proteins: A review. J. Raman Spectrosc. 2013, 44 (8), 1061-1076.

(38) Chen, C.; Yao, T.; Tu, S.; Xu, W.; Han, Y.; Zhou, P. In situ microscopic studies on the structures and phase behaviors of SF/PEG films using solid-state NMR and Raman imaging. Phys. Chem. Chem. Phys. 2016, 18 (24), 16353-16360.

(39) Turk, B.; Turk, V.; Turk, D. Structural and functional aspects of papain-like cysteine proteinases and their protein inhibitors. Biol. Chem. 1997, 378 (3-4), 141-150.

(40) Lu, Q.; Zhang, B.; Li, M.; Zuo, B.; Kaplan, D. L.; Huang, Y.; $\mathrm{Zhu}, \mathrm{H}$. Degradation mechanism and control of silk fibroin. Biomacromolecules 2011, 12, 1080-1086.

(41) Numata, K.; Cebe, P.; Kaplan, D. L. Mechanism of enzymatic degradation of beta-sheet crystals. Biomaterials 2010, 31 (10), 29262933. 